\title{
Preparation of phase pure, dense fine grained ceramics by conventional and spark plasma sintering of La-substituted $\mathrm{BiFeO}_{3}$ nanoparticles
}

Antonio Perejón ${ }^{\mathrm{a}, *}$, Pedro E. Sánchez-Jiménez ${ }^{\mathrm{a}}$, Rosalía Poyato ${ }^{\mathrm{a}}$, Nahum Masób, Anthony R. West ${ }^{\mathrm{b}}$, José M. Criado ${ }^{\mathrm{a}}$, Luis A. Pérez-Maqueda ${ }^{\mathrm{a}, *}$

${ }^{a}$ Instituto de Ciencia de Materiales de Sevilla (CSIC-Universidad de Sevilla). C. Américo Vespucio 49, Sevilla 41092. Spain

${ }^{b}$ Department of Materials Science and Engineering, University of Sheffield, S1 3JD Sheffield, UK

*Corresponding authors:

antonio.perejon@icmse.csic.es

Instituto de Ciencia de Materiales de Sevilla (CSIC-Universidad de Sevilla).

C. Américo Vespucio 49, Sevilla 41092. Spain

Tel. (+34) 954489500

Fax (+34) 954460165

maqueda@cica.es

Instituto de Ciencia de Materiales de Sevilla (CSIC-Universidad de Sevilla).

C. Américo Vespucio 49, Sevilla 41092. Spain

Tel. $(+34) 954489548$

Fax (+34) 954460165 


\title{
Preparation of phase pure, dense fine grained ceramics by conventional and spark plasma sintering of La-substituted $\mathrm{BiFeO}_{3}$ nanoparticles
}

\author{
Antonio Perejón ${ }^{\mathrm{a}, *}$, Pedro E. Sánchez-Jiménez ${ }^{\mathrm{a}}$, Rosalía Poyato ${ }^{\mathrm{a}}$, Nahum Masó ${ }^{\mathrm{b}}$, \\ Anthony R. West ${ }^{b}$, José M. Criado ${ }^{a}$, Luis A. Pérez-Maqueda ${ }^{a}$ * \\ ${ }^{a}$ Instituto de Ciencia de Materiales de Sevilla (CSIC-Universidad de Sevilla). C. Américo Vespucio 49, \\ Sevilla 41092. Spain \\ ${ }^{b}$ Department of Materials Science and Engineering, University of Sheffield, S1 3JD Sheffield, UK
}

\begin{abstract}
High density ceramics of the system $\mathrm{Bi}_{1-\mathrm{x}} \mathrm{La}_{\mathrm{x}} \mathrm{FeO}_{3}, 0 \leq \mathrm{x} \leq 0.15$, have been prepared starting from nanoparticles obtained by mechanosynthesis. The ceramics have been sintered conventionally at $850^{\circ} \mathrm{C}$ and by spark plasma sintering (SPS). Sintering conditions have been optimized to obtain single phase ceramics, and the microstructure of the ceramics has been compared. Ceramics prepared conventionally present grain sizes from $5 \mu \mathrm{m}$ to less than $1 \mu \mathrm{m}$, whereas grain sizes by SPS are in the range from $50-100 \mathrm{~nm}$, which demonstrates that it is possible to obtain nanostructured ceramics of La-substituted $\mathrm{BiFeO}_{3}$ using mechanosynthesis followed by SPS at low temperature $\left(625^{\circ} \mathrm{C}-650^{\circ} \mathrm{C}\right)$. The as-prepared SPS ceramics show low resistivity, indicating some reduction in the samples. However, after an oxidative anneal in air, ceramics are highly insulating at room temperature and electrically homogeneous. The high quality of the ceramics has also been demonstrated by XRD, EDX, Raman and DSC.
\end{abstract}

Keywords: $\mathrm{BiFeO}_{3}$; La-substituted bismuth ferrite; mechanosynthesis; sintering; spark plasma sintering 


\section{Introduction}

The preparation of phase-pure dense $\mathrm{BiFeO}_{3}$ ceramics presents many difficulties. The main ones are the presence of impurities in the final product, mainly $\mathrm{Bi}_{25} \mathrm{FeO}_{39}$ and $\mathrm{Bi}_{2} \mathrm{Fe}_{4} \mathrm{O}_{9}$, and the difficulty to obtain dense ceramics with high resistivity. Thus, it is difficult to obtain samples with densities above $90 \%$ of the theoretical density, which is important when studying electrical properties because, in general, a high porosity decreases the permittivity. Powders obtained by conventional solid state reaction do not give ceramic materials with high densities. ${ }^{1}$ Recently, the major processing issues, paying special attention to the thermodynamic and kinetic origin of secondary phases, have been reviewed. ${ }^{2}$ Thus, the presence of secondary phases could be due to a number of reasons, including thermal decomposition of $\mathrm{BiFeO}_{3} ;{ }^{3,4}$ presence of impurities in the starting $\mathrm{Bi}_{2} \mathrm{O}_{3}$ and $\mathrm{Fe}_{2} \mathrm{O}_{3}$ powders; ${ }^{5}$ reaction of the ceramic with alumina or quartz crucibles; ${ }^{2,6}$ segregation and peritectic decomposition at relatively low temperature of the $\mathrm{Bi}_{25} \mathrm{FeO}_{39}$ phase, which is the first phase formed from the solid state reaction between $\mathrm{Bi}_{2} \mathrm{O}_{3}$ and $\mathrm{Fe}_{2} \mathrm{O}_{3}$, before the formation of the perovskite phase is complete. ${ }^{2,7}$ Consequently, ceramics prepared by conventional solid-state reactions are not pure phase materials and in general present high leakage current together with weak magnetic properties and low magnetoelectric coupling coefficient, limiting the technological applications of $\mathrm{BiFeO}_{3}$. Different methods have been proposed to solve these problems. Despite the many synthesis methods used and the numerous methods for sintering ceramics, few authors detail the density of the samples obtained. ${ }^{8-12}$ It has been reported that, by rapid liquid phase sintering, phase pure $\mathrm{BiFeO}_{3}$ is obtained with density of $92 \%,{ }^{13,14}$ and by sonochemical and microemulsion techniques, nanosized $\mathrm{BiFeO}_{3}$ has been prepared that densified to approximately $92 \%$. ${ }^{15}$

There is little data in the literature about the density of samples prepared in the system $\mathrm{Bi}_{1}$ ${ }_{x} \mathrm{La}_{\mathrm{x}} \mathrm{FeO}_{3}$. ${ }^{16-18} \mathrm{~A}$ modified thermal process was used to prepare $\mathrm{La}_{0.1} \mathrm{Bi}_{0.9} \mathrm{FeO}_{3}$ ceramics with high resistivity, obtaining samples with densities of about $90 \% .{ }^{19}$ The quality of the powders and the density of the green pellets are critical for obtaining dense pellets with good electrical properties of samples with $0 \leq \mathrm{x} \leq 0.2$ prepared using a modified Pechini approach. ${ }^{20}$

Spark plasma sintering (SPS) has become an important technique to obtain high density ceramics, ${ }^{21,22}$ and some authors have used this technique for sintering $\mathrm{BiFeO}_{3}$ ceramics, starting from powders prepared by simultaneous precipitation routes, Pechini's method, sol-gel method or conventional solid state reaction. ${ }^{23-26}$ Different experimental conditions have been used in terms of sintering temperature and applied pressure to obtain high density ceramics. However the values of density are sometimes not reported or the ceramics obtained are not phase pure. SPS has been also applied to sinter $\mathrm{BiFeO}_{3}$ samples prepared by mechanosynthesis. ${ }^{27,28}$

Regarding the use of SPS for sintering La-substituted $\mathrm{BiFeO}_{3}$, to our knowledge there is only one report, for $\mathrm{Bi}_{0.87} \mathrm{La}_{0.05} \mathrm{~Tb}_{0.08} \mathrm{FeO}_{3}$. The sample was prepared by a modified Pechini method 
starting from the corresponding metal nitrates, and the powders were sintered by SPS at $750^{\circ} \mathrm{C}$ and $50 \mathrm{MPa}{ }^{29}$

In this work, the optimum conditions for processing mechanosynthesized $\mathrm{Bi}_{1-\mathrm{x}} \mathrm{La}_{\mathrm{x}} \mathrm{FeO}_{3}(\mathrm{x}=0$, $0.02,0.07$ and 0.15 ) powders by both conventional and SPS techniques are studied. The analysis of the influence of sintering conditions on the density and purity of the pellets obtained was performed by characterizing the sintered materials by X-ray diffraction (XRD) and calorimetric, microscopic and spectroscopic techniques.

\section{Material and methods}

\subsection{Sample preparation}

Samples of the system $\mathrm{Bi}_{(1-\mathrm{x})} \mathrm{La}_{\mathrm{x}} \mathrm{FeO}_{3}(0 \leq \mathrm{x} \leq 0.15)$ were prepared by mechanosynthesis using $\mathrm{Bi}_{2} \mathrm{O}_{3}$ (Sigma-Aldrich 223891-500G, $10 \mu \mathrm{m}, 99.9 \%$ pure), $\mathrm{Fe}_{2} \mathrm{O}_{3}$ (Sigma-Aldrich 310050-500G, $<5 \mu \mathrm{m}, \geq 99 \%$ pure) and $\mathrm{La}_{2} \mathrm{O}_{3}$ (Sigma-Aldrich L4000-100G, $\geq 99 \%$ pure). Full experimental details are found in Ref 30. Stoichiometric amounts of the oxides were mechanically treated in a modified planetary ball mill Fritsch Pulverisette 7 (Fritsch) under 7 bars of oxygen pressure. The mill was modified by incorporating a rotary valve that allows connection of the jar (sealed with a Viton o-ring and equipped with a male taper straight adaptor) and the gas cylinder during milling. Thus, the pressure inside the jar was maintained constant during the entire treatment even if gas was consumed by the reaction. In all experiments, the jars were purged several times with oxygen and the desired pressure selected and maintained during milling. The spinning rates of both the supporting disc and the superimposed rotation in the opposite direction of the jar was set at $700 \mathrm{rpm}$ and the powder-to-ball mass ratio was set at 1:20 in all cases. A hardened steel jar ( $80 \mathrm{~cm}^{3}$ volume) and balls ( 9 balls, $15 \mathrm{~mm}$ diameter) were used in all experiments.

Two methods were used to sinter pellets of the mechanosynthesised samples: conventional sintering and spark plasma sintering (SPS). Conventional sintering was carried out by heating green pellets at atmospheric pressure in air. Thus, $400 \mathrm{mg}$ of the nanometric powders prepared by mechanosynthesis for each composition were placed in a hardened steel die, $6.35 \mathrm{~mm}$ diameter, and different uniaxial pressures applied to study the influence of green pellet density on the final densities obtained after heating. Sintering was followed by dilatometric analyses, placing the green pellets in a Linseis TMA model PT1000 in $100 \mathrm{~cm}^{3} \min ^{-1}$ airflow using $10{ }^{\circ} \mathrm{C}$ $\min ^{-1}$ heating rate from $200^{\circ} \mathrm{C}$ to $850^{\circ} \mathrm{C}$. All samples were heated to the same maximum temperature during 1 minute to avoid possible decomposition or the formation of secondary phases. Densities of the green pellets were calculated geometrically by the equation $\rho=\mathrm{m} \mathrm{V}^{-1}$, while the densities of sintered pellets were obtained by the Archimedes' principle, using water as an immersion medium. 
Spark plasma sintering of the powders was performed in a SPS instrument, Model 515S (SPS Dr Sinter Inc., Kanagawa, Japan) in vacuum in a $10 \mathrm{~mm}$ diameter cylindrical graphite die/punch setup, under different uniaxial pressures, heating rate of $250^{\circ} \mathrm{C} \min ^{-1}$ and at different final temperatures and isothermal times (5 and 10 minutes), with the objective of obtaining high densities and pure phases for each composition. The following parameters were controlled: applied uniaxial pressure, final temperature and isothermal time. Temperature was measured using a thermocouple placed in a bore hole in the middle part of the graphite die. The sintered ceramics, $\sim 10 \mathrm{~mm}$ in diameter and $\sim 2 \mathrm{~mm}$ thick, were polished to eliminate carbon from the surface.

\subsection{Characterization}

X-ray diffraction patterns were collected with a Panalytical X'Pert Pro diffractometer working at $45 \mathrm{kV}$ and $40 \mathrm{~mA}$, using $\mathrm{CuK} \alpha$ radiation and equipped with a $\mathrm{X}$ 'Celerator detector and a graphite diffracted beam monochromator.

The microstructure of the pellets was studied by scanning electron microscopy (SEM). SEM micrographs were obtained in a Hitachi S-4800 microscope equipped with energy dispersive Xray spectrometer (EDAX) attachment. Pellets were thermally etched for 30 minutes at $90 \%$ of the sintering temperature to reveal the grain boundaries. EDX spectra were recorded for a semiquantitative study of the stoichiometry of pellets after sintering.

Raman spectra were collected with a dispersive Horiva Jobin Yvon LabRam HR800 microscope with a $20 \mathrm{~mW}$ green laser $(532.14 \mathrm{~nm})$ and a $100 \times$ objective with a confocal pinhole of $10 \mu \mathrm{m}$. Multiferroic properties of samples obtained by SPS were analyzed by differential scanning calorimetry (DSC). Small pieces of pellets were placed in alumina pans and heated from $250^{\circ} \mathrm{C}$ to $860^{\circ} \mathrm{C}$ at $10^{\circ} \mathrm{C} \mathrm{min}^{-1}$ in $100 \mathrm{~cm}^{3} \mathrm{~min}^{-1}$ airflow. The temperatures of the transitions were taken as the onset of the peaks.

For electrical property measurements, pellets were $\mathrm{Au}$ sputtered-coated using an Emitech K575X Sputter Coater. Impedance measurements used a combination of Agilent 4294A and E4980A impedance analysers over the frequency range $5 \mathrm{~Hz}$ to $10 \mathrm{MHz}$, with an ac measuring voltage of $0.1 \mathrm{~V}$ and over the temperature range from room temperature to $400{ }^{\circ} \mathrm{C}$. Impedance data were corrected for pellet geometry and for blank capacitance of the jig. Conductivity and capacitance data are reported in units of $\mathrm{Scm}^{-1}$ and $\mathrm{Fcm}^{-1}$, respectively, that refer to correction for only the overall sample geometry. 


\section{Results and discussion}

\subsection{Conventional sintering}

The influence of density of the green pellets on the final density of the sintered ones was studied by preparing pellets of $\mathrm{BiFeO}_{3}$ in a hardened steel die and applying different uniaxial pressures. Table 1 shows the density of the pellets sintered in the TMA at $850^{\circ} \mathrm{C}$ for 1 minute as a function of the pressure used to make the pellets. It was not possible to prepare green pellets at pressures above $930 \mathrm{MPa}$ due to delamination. As has been observed by Jiang et al in samples prepared by a modified Pechini approach, ${ }^{20}$ from Table 1 a clear influence of the densities of the green pellets on the densities of the pellets after thermal treatment is observed. Thus, it is possible to obtain densities of $92 \%$ when the green pellet has a density of $72.5 \%$. Taking into account these results, all green pellets for each composition were prepared applying uniaxial pressure of 930 $\mathrm{MPa}$.

Table 1. Relation between applied pressure, density of green pellets and density of pellets sintered at $850^{\circ} \mathrm{C}$ for $\mathrm{BiFeO}_{3}$.

\begin{tabular}{ccc}
$\begin{array}{c}\text { Pressure } \\
(\mathrm{MPa})\end{array}$ & $\begin{array}{c}\rho \text { green pellets } \\
(\%)\end{array}$ & $\begin{array}{c}\rho \text { sintered } \\
\text { pellets }(\%)\end{array}$ \\
310 & 65.0 & 87.2 \\
620 & 69.4 & 89.1 \\
930 & 72.5 & 92.0 \\
\hline
\end{tabular}

Densities were also compared with the density of a sample prepared by conventional solid state reaction. Thus, commercial $\mathrm{Bi}_{2} \mathrm{O}_{3}$ and $\mathrm{Fe}_{2} \mathrm{O}_{3}$ powders were mixed using ethanol in an agate mortar and heated to $800^{\circ} \mathrm{C}$ for 30 minutes to obtain $\mathrm{BiFeO}_{3}$ powders. Then, the powders were hand-milled in the mortar, compacted in a $6.35 \mathrm{~mm}$ die at a uniaxial pressure of $930 \mathrm{MPa}$ and the resulting green pellet heated at $850^{\circ} \mathrm{C}$ for 1 minute. A final density of $82.5 \%$ was obtained which is significantly less than that obtained using mechanosynthesized $\mathrm{BiFeO}_{3}$ powders.

Fig. 1 presents the dilatometric curve for $\mathrm{BiFeO}_{3}$ green pellet together with the $\mathrm{X}$-ray diffraction pattern of the sintered sample. An initial thermal expansion is observed in the dilatometric curve (Fig. 1a) until approximately $395^{\circ} \mathrm{C}$, when the pellet begins to contract in several overlapping stages. The last stage takes place from $725^{\circ} \mathrm{C}$, with a sharp contraction until $850^{\circ} \mathrm{C}$. The X-ray diffraction pattern (Fig. 1b) shows that the sintered pellet consists of single-phase $\mathrm{BiFeO}_{3}$. Dilatometric curves and the corresponding X-ray diffraction patterns for sintered pellets of $\mathrm{x}=$ 0.02, 0.07 and 0.15 are shown in the Supplementary Data, Figs. S1-S3. All pellets present 
similar behavior to $\mathrm{BiFeO}_{3}$, with an initial thermal expansion and a contraction from approximately $395^{\circ} \mathrm{C}$. The X-ray diffraction patterns show that the sintered pellets are singlephase in all cases.
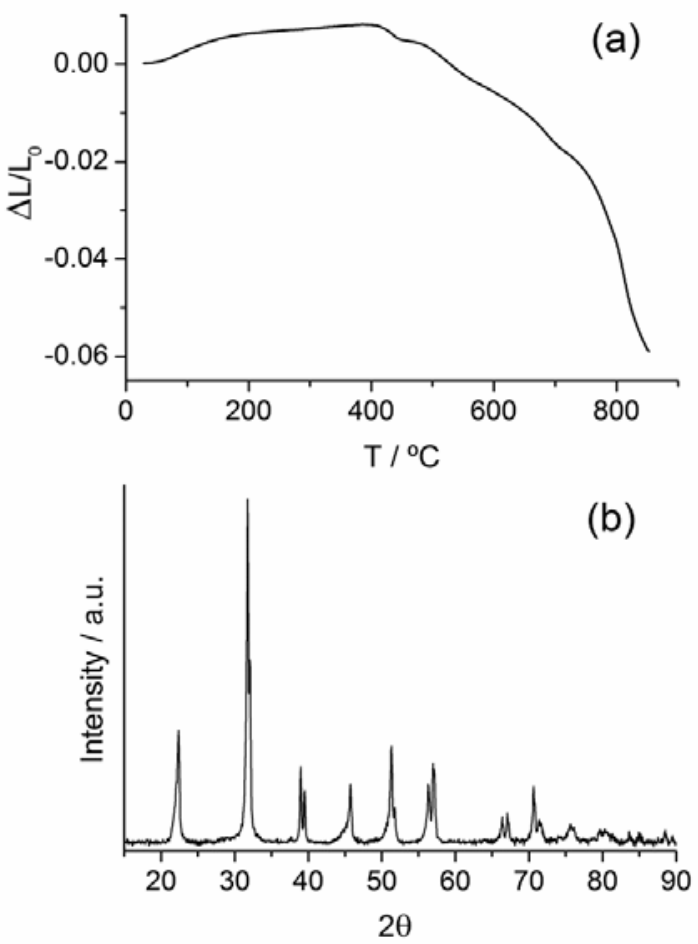

Fig. 1. (a) Dilatometric curve for a $\mathrm{BiFeO}_{3}$ pellet and (b) corresponding X-ray diffraction pattern registered after sintering at $850^{\circ} \mathrm{C}$.

The relation between the densities of the green and sintered pellets for the samples, $0 \leq \mathrm{x} \leq 0.15$ sintered conventionally is presented in table 2; densities of sintered pellets are in the range 89$92 \%$.

Table 2. Relation between the densities of green pellets and pellets sintered at $850^{\circ} \mathrm{C}$, as a function of lanthanum content $(\mathrm{x})$.

\begin{tabular}{ccc}
$\begin{array}{c}\text { Composition } \\
(\mathrm{x})\end{array}$ & $\begin{array}{c}\rho \text { green pellets } \\
(\%)\end{array}$ & $\begin{array}{c}\rho \text { sintered pellets } \\
(\%)\end{array}$ \\
0.00 & 72.5 & 92.0 \\
0.02 & 74.9 & 91.0 \\
0.07 & 74.0 & 90.2 \\
0.15 & 74.2 & 89.3 \\
\hline
\end{tabular}

SEM micrographs of pellets sintered at $850^{\circ} \mathrm{C}$ and thermally etched, Fig. 2, show irregular grains of different size. $\mathrm{BiFeO}_{3}$ (Fig. 2a) and $\mathrm{Bi}_{0.98} \mathrm{La}_{0.02} \mathrm{FeO}_{3}$ (Fig. 2b) present very similar 
grain size, of approximately 1-5 $\mu \mathrm{m}$. Grain size decreases to 1-2 $\mu \mathrm{m}$ for $\mathrm{Bi}_{0.93} \mathrm{La}_{0.07} \mathrm{FeO}_{3}$, Fig. 2c, and $<1 \mu \mathrm{m}$ for $\mathrm{Bi}_{0.85} \mathrm{La}_{0.15} \mathrm{FeO}_{3}$, Fig. $2 \mathrm{~d}$.
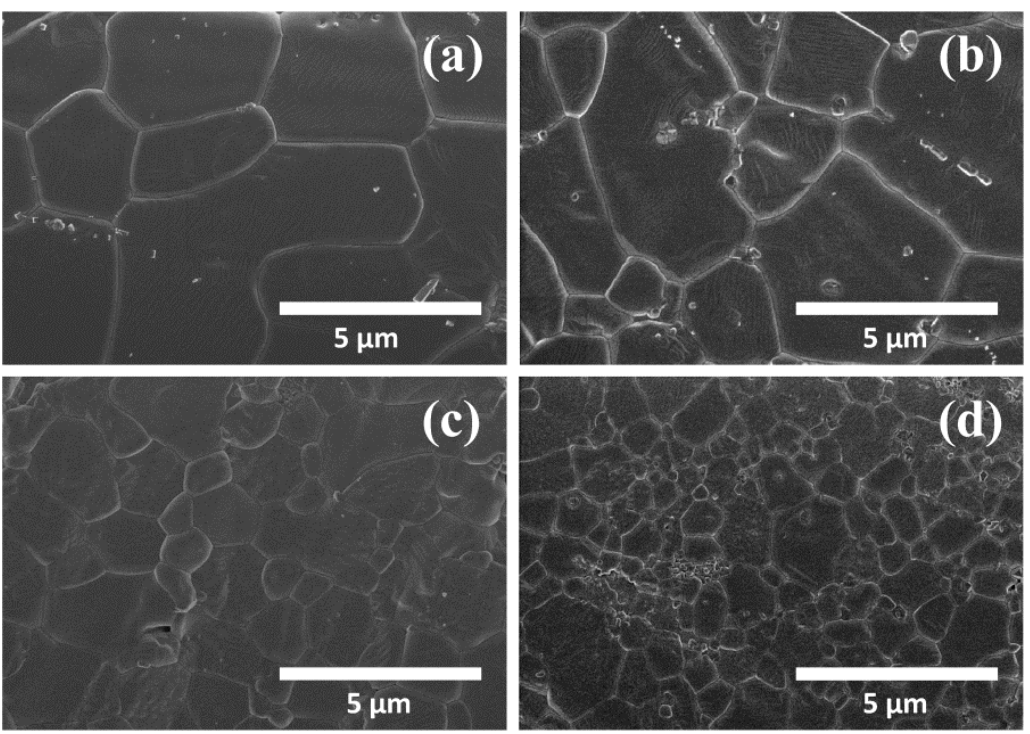

Fig. 2. SEM micrographs of pellets sintered conventionally at $850^{\circ} \mathrm{C}$ and thermal etched for (a) $\mathrm{BiFeO}_{3}$, (b) $\mathrm{Bi}_{0.98} \mathrm{La}_{0.02} \mathrm{FeO}_{3}$, (c) $\mathrm{Bi}_{0.93} \mathrm{La}_{0.07} \mathrm{FeO}_{3}$ and (d) $\mathrm{Bi}_{0.85} \mathrm{La}_{0.15} \mathrm{FeO}_{3}$.

Fig. 3 presents EDX spectra for these pellets. In the inset table of each spectrum the semiquantitative chemical analysis is shown. From these data, the materials have maintained their stoichiometry after sintering: in all cases, the results match approximately the nominal stoichiometry.
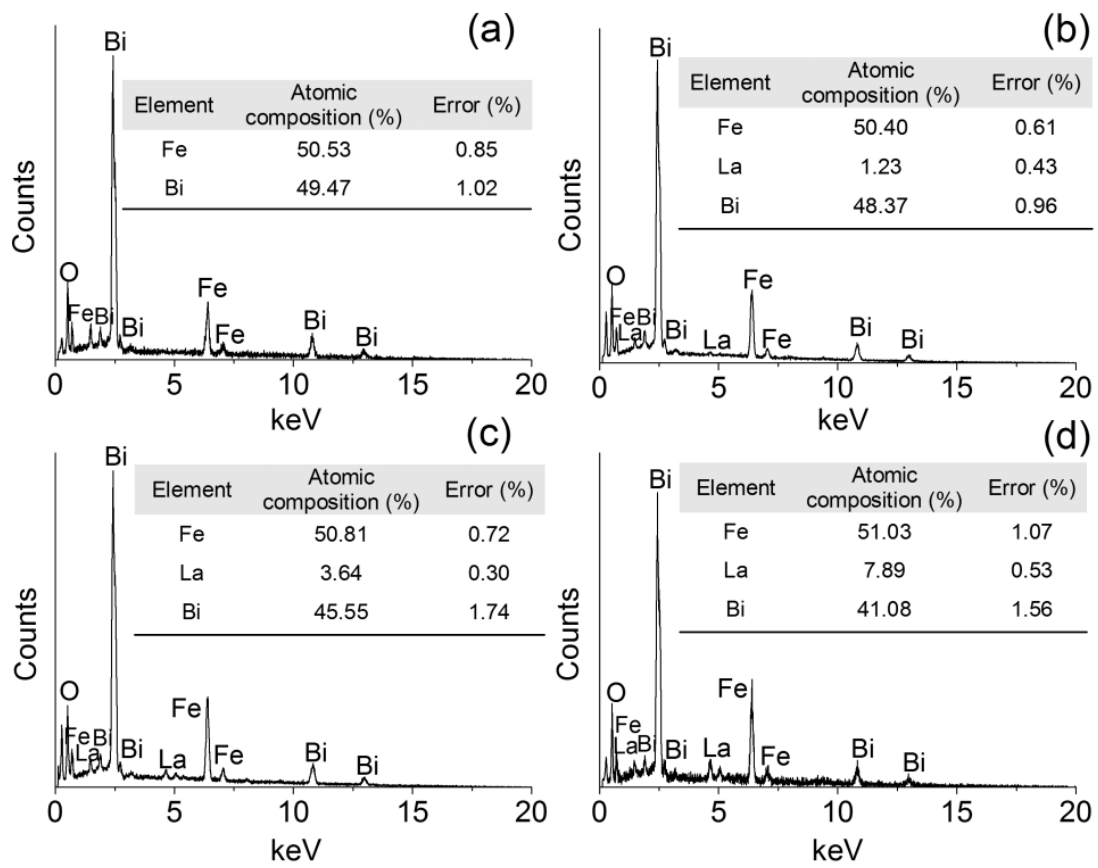

Fig. 3. EDX spectra of conventionally sintered pellets at $850^{\circ} \mathrm{C}$ and thermal etched for (a) $\mathrm{BiFeO}_{3}$, (b) $\mathrm{Bi}_{0.98} \mathrm{La}_{0.02} \mathrm{FeO}_{3}$, (c) $\mathrm{Bi}_{0.93} \mathrm{La}_{0.07} \mathrm{FeO}_{3}$ and (d) $\mathrm{Bi}_{0.85} \mathrm{La}_{0.15} \mathrm{FeO}_{3}$. The inset tables show the semiquantitative analysis of the elements Fe:La:Bi. 
The density of sintered pellets depends on the density of the green pellets and La content when sintered conventionally. Thus, as La content increases the relative density of pellets sintered at the same temperature decreases (Table 2). This may be because to prepare high density pellets of $\mathrm{LaFeO}_{3}$, it is necessary to heat samples at much higher temperatures. ${ }^{31}$

Pellet quality was also tested by Raman spectroscopy for each composition, Fig. 4. The characteristic lines of rhombohedral $\mathrm{R} 3 \mathrm{c} \mathrm{BiFeO} 3$ are clearly observed, at 172, 224 and $422 \mathrm{~cm}^{-1}$ for the A1 modes and 261, 288, 367, 482, 523 and $620 \mathrm{~cm}^{-1}$ for the E modes. Bands at low Raman shift, associated with the Bi-O bonds, reduce in intensity when $\mathrm{Bi}$ is substituted by La; bands at high Raman shift, associated with the internal vibration of $\mathrm{FeO}_{6}$ units, present small distortions due to deformation created in the structure as La content increases. This behavior has been previously observed by several authors. ${ }^{32,33}$

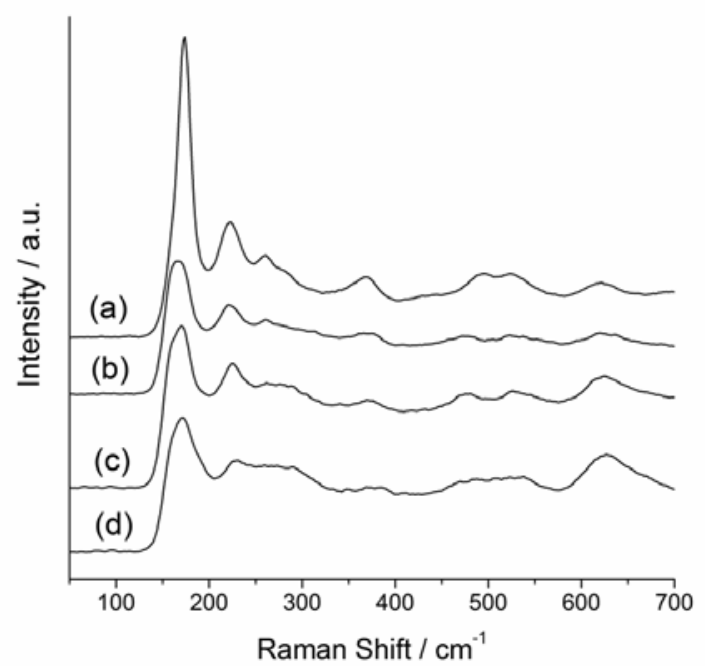

Fig. 4. Raman spectra for the conventionally sintered pellets: (a) $\mathrm{BiFeO}_{3}$, (b) $\mathrm{Bi}_{0.98} \mathrm{La}_{0.02} \mathrm{FeO}_{3}$, (c) $\mathrm{Bi}_{0.93} \mathrm{La}_{0.07} \mathrm{FeO}_{3}$ and (d) $\mathrm{Bi}_{0.85} \mathrm{La}_{0.15} \mathrm{FeO}_{3}$.

\subsection{Spark plasma sintering, SPS}

The evolution of a typical SPS experiment is summarized in Fig. $5 \mathrm{a}$ where temperature, $\mathrm{T} /{ }^{\circ} \mathrm{C}$, current, I/A, shrinkage, $\mathrm{z} / \mathrm{mm}$, and pressure inside the chamber, $\mathrm{p} / \mathrm{Pa}$, are shown against time. The temperature followed adequately the heating ramp; a maximum current of $477.25 \mathrm{~A}$ was reached; the pressure was approximately constant in the entire experiment; the shrinkage increased from the beginning of the experiment and took place in two stages during heating, stabilized during the isothermal treatment and increased again on cooling, probably due to thermal expansion of the graphite die and the chamber. Fig. 5b shows, as an example, two pellets sintered by SPS and polished to eliminate carbon from the surface. 


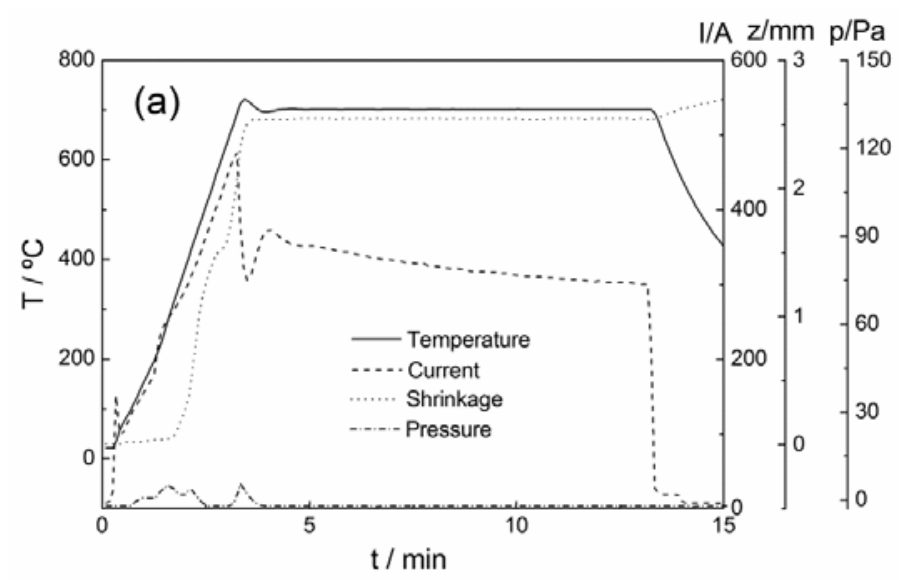

(b)

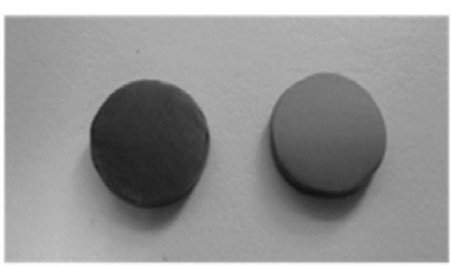

Fig. 5. (a) Evolution of temperature, current, shrinkage and pressure inside the chamber during SPS. (b) Pellets sintered by SPS, for compositions $x=0.07$ (left) and $x=0.02$ (right).

Different experimental conditions were tested to optimize the sintering of $\mathrm{BiFeO}_{3}$ by changing the heating schedule and the applied pressure. Results for three of the variables tested are shown in Table 3 and compared with the final densities. Both pressure and temperature play an important role. The densities were similar when the samples were heated at high $\left(700^{\circ} \mathrm{C}-750^{\circ} \mathrm{C}\right)$ and low temperatures $\left(625^{\circ} \mathrm{C}\right)$, but were lower at an intermediate temperature $\left(675^{\circ} \mathrm{C}\right)$.

Table 3. Experimental conditions used for sintering $\mathrm{BiFeO}_{3}$ powders by SPS and resulting densities.

\begin{tabular}{ccccc} 
Sample & $\begin{array}{c}\text { Temperature } \\
\left({ }^{\circ} \mathrm{C}\right)\end{array}$ & $\begin{array}{c}\text { Isotherm } \\
(\mathrm{min})\end{array}$ & $\begin{array}{c}\text { Pressure } \\
(\mathrm{MPa})\end{array}$ & $\rho(\%)$ \\
$\mathrm{a}$ & 750 & 5 & 75 & 97.7 \\
\hline $\mathrm{b}$ & 700 & 10 & 70 & 97.4 \\
\hline $\mathrm{c}$ & 675 & 10 & 75 & 94.3 \\
\hline $\mathrm{d}$ & 625 & 5 & 100 & 97.6 \\
\hline
\end{tabular}

Fig. 6 shows the diffraction patterns for pellets sintered under the conditions presented in Table 3. For samples sintered at $750^{\circ} \mathrm{C}, 700^{\circ} \mathrm{C}$ and $675^{\circ} \mathrm{C}$, partial decomposition occurred and weak reflections corresponding to metallic bismuth and iron oxides appear. Therefore, partial reduction of the samples was induced by the reducing conditions of the experiment: the samples 
were heated in vacuum and confined in a graphite die while a high density current was applied. Consequently, it is necessary to decrease the sintering temperature to avoid $\mathrm{BiFeO}_{3}$ reduction. At $625^{\circ} \mathrm{C}$, the samples are single-phase $\mathrm{BiFeO}_{3}$ and the density is as high as for the pellets heated at higher temperatures.
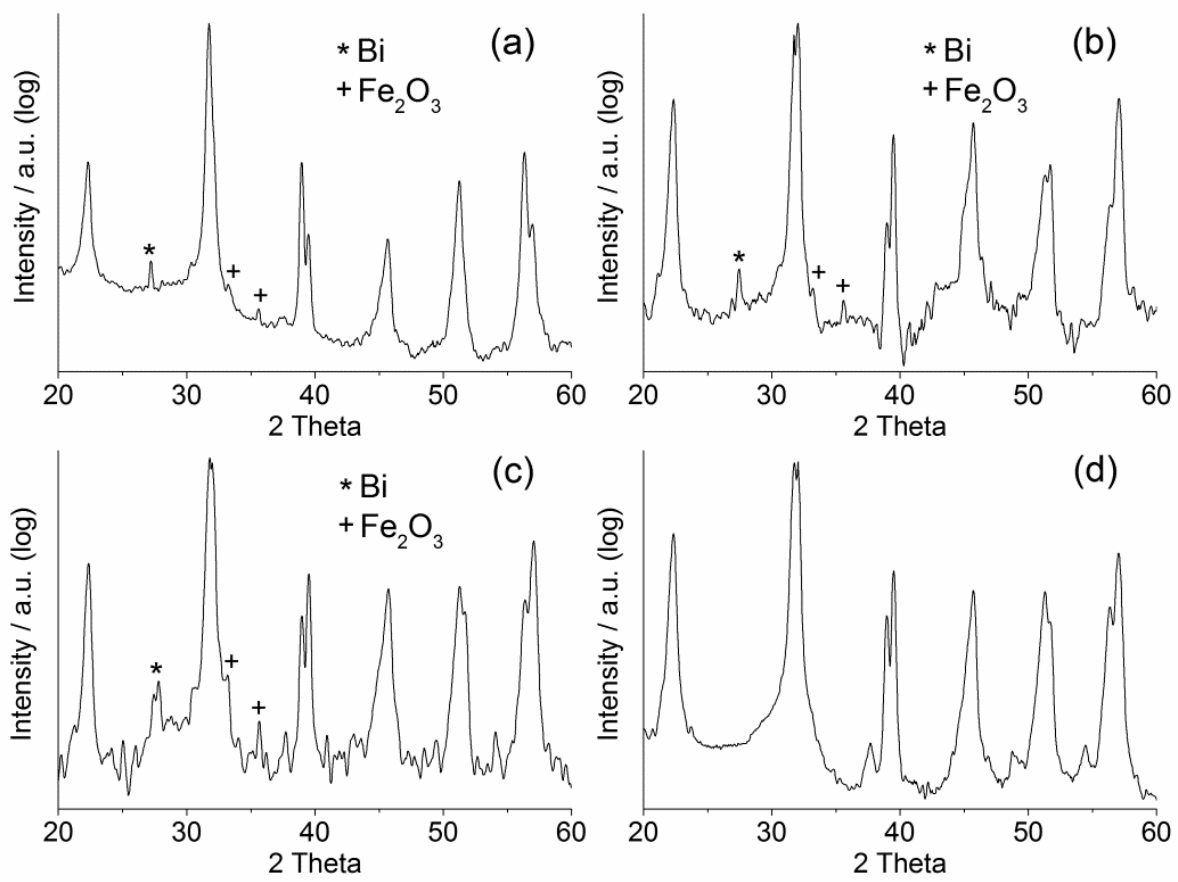

Fig. 6. XRD for pellets of $\mathrm{BiFeO}_{3}$ sintered by SPS under the conditions shown in Table 3: (a) $750^{\circ} \mathrm{C}$, (b) $700^{\circ} \mathrm{C}$, (c) $675^{\circ} \mathrm{C}$, (d) $625^{\circ} \mathrm{C}$.

Similar behavior was observed for the La-substituted samples. For $\mathrm{Bi}_{0.98} \mathrm{La}_{0.02} \mathrm{FeO}_{3}$, higher densities are obtained than for $\mathrm{BiFeO}_{3}$ sintered under the same conditions. Pellets sintered at $700^{\circ} \mathrm{C}$ present reflections of metallic $\mathrm{Bi}$, while at $675^{\circ} \mathrm{C}$ a phase pure material was obtained. On reducing the sintering temperature to $625^{\circ} \mathrm{C}$ and increasing the applied pressure, the density also increased. Experimental conditions and diffraction patterns are shown in the Supplementary Data (Table S1 and Fig. S4). For $\mathrm{Bi}_{0.93} \mathrm{La}_{0.07} \mathrm{FeO}_{3}$, at lower temperatures and higher pressures the quality and density of the pellets are also improved, in such a way that on sintering at $650^{\circ} \mathrm{C}$ and $75 \mathrm{MPa}$, the density obtained is almost the theoretical density (99.1\%). If the experiment is carried out at high temperature $\left(800^{\circ} \mathrm{C}\right), \mathrm{Bi}^{3+}$ is reduced to metallic bismuth and $\mathrm{Fe}^{3+}$ is partially reduced yielding magnetite $\left(\mathrm{Fe}_{3} \mathrm{O}_{4}\right)$ (See Supplementary Data, Table S2 and Fig. S5). At $675^{\circ} \mathrm{C}$ and $70 \mathrm{MPa}$, the sample is partially reduced again to metallic bismuth and $\mathrm{Fe}_{2} \mathrm{O}_{3}$. Therefore, optimal conditions for sintering $\mathrm{Bi}_{0.93} \mathrm{La}_{0.07} \mathrm{FeO}_{3}$, in terms of purity and density, are $650^{\circ} \mathrm{C}$ and $75 \mathrm{MPa}$. These conditions are also optimal for $\mathrm{Bi}_{0.85} \mathrm{La}_{0.15} \mathrm{FeO}_{3}$ sintering, with a density of 97.4\% (See Table S3 and Fig. S6 in Supplementary Data). 
Microstructure of pellets sintered by SPS was also studied by SEM. Micrographs were recorded after polishing and thermal etching (Fig. 7). All pellets showed nanosized grains of 50-100 nm, demonstrating that it is possible to obtain nanostructured ceramics of La-substituted $\mathrm{BiFeO}_{3}$ using mechanosynthesis followed by SPS. EDX spectra of the samples shown in Fig. 7 and presented in Fig. 8 reveal that stoichiometry is maintained in all the compositions.
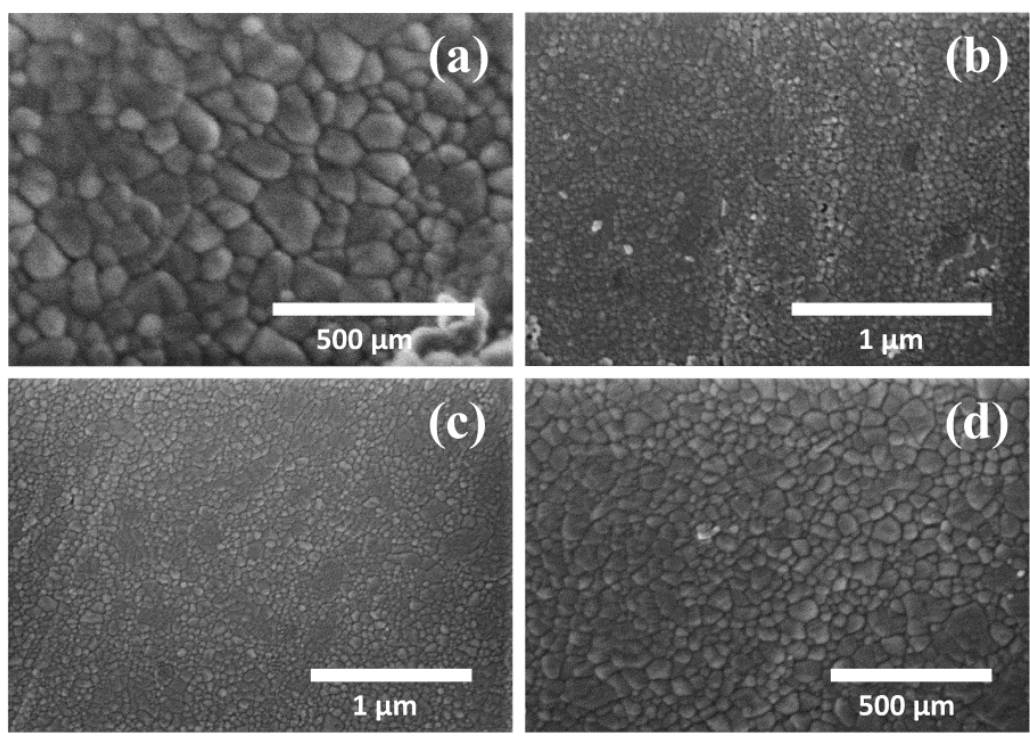

Fig. 7. SEM micrographs of the pellets sintered by SPS and thermal etched for (a) $\mathrm{BiFeO}_{3}$, (b) $\mathrm{Bi}_{0.98} \mathrm{La}_{0.02} \mathrm{FeO}_{3}$, (c) $\mathrm{Bi}_{0.93} \mathrm{La}_{0.07} \mathrm{FeO}_{3}$ and (d) $\mathrm{Bi}_{0.85} \mathrm{La}_{0.15} \mathrm{FeO}_{3}$.
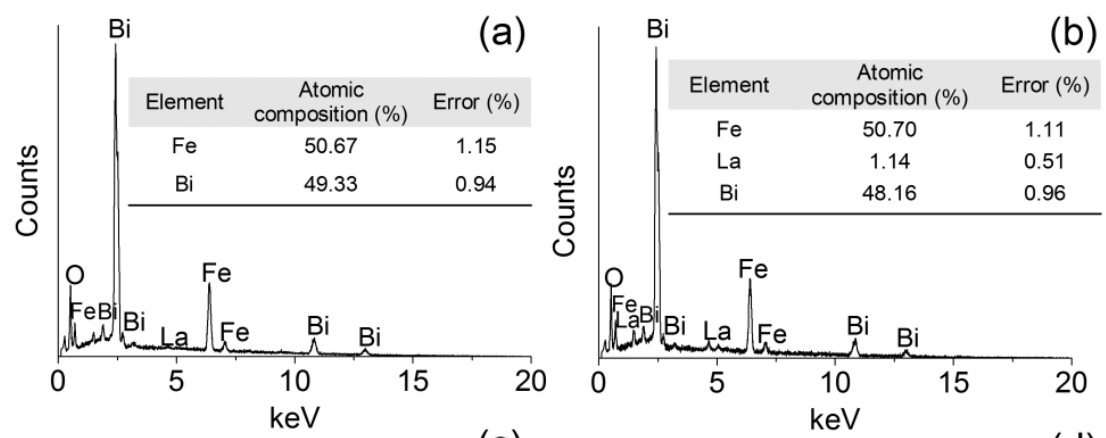

(c)
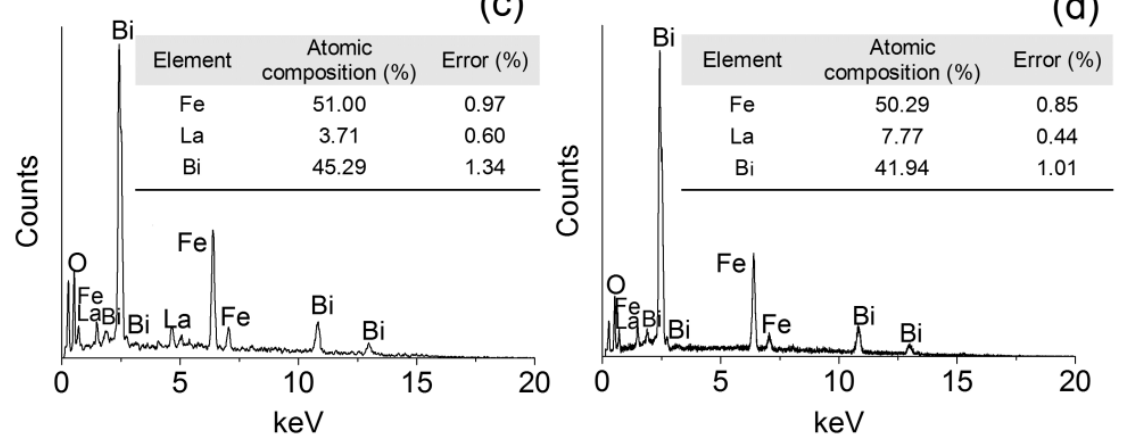

Fig. 8. EDX spectra of the SPS sintered pellets and thermal etched for (a) $\mathrm{BiFeO}_{3}$, (b) $\mathrm{Bi}_{0.98} \mathrm{La}_{0.02} \mathrm{FeO}_{3}$, (c) $\mathrm{Bi}_{0.93} \mathrm{La}_{0.07} \mathrm{FeO}_{3}$ and (d) $\mathrm{Bi}_{0.85} \mathrm{La}_{0.15} \mathrm{FeO}_{3}$. The inset tables show the semiquantitative analysis of the elements Fe:La:Bi. 
Fig. 9 shows Raman spectra; typical bands of $\mathrm{BiFeO}_{3}$ perovskite are even clearer, with approximately the same Raman shifts as for pellets sintered conventionally, demonstrating the quality of the samples.

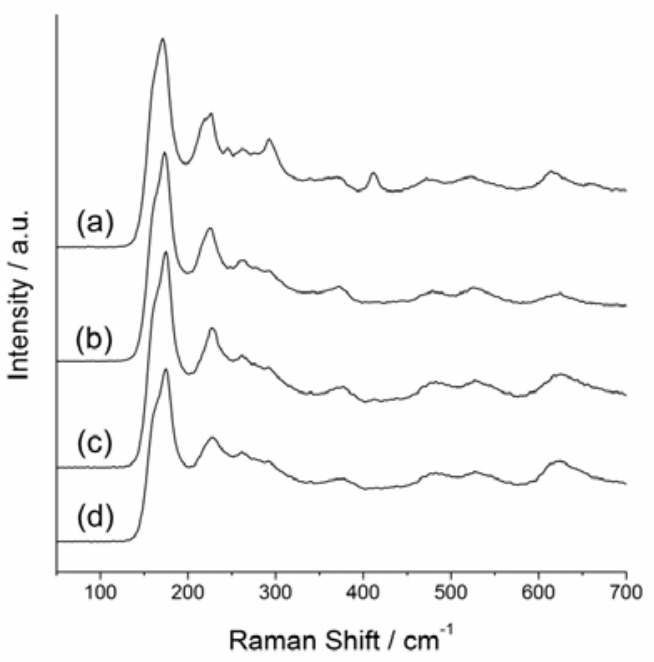

Fig. 9. Raman spectra for SPS sintered pellets: (a) $\mathrm{BiFeO}_{3}$, (b) $\mathrm{Bi}_{0.98} \mathrm{La}_{0.02} \mathrm{FeO}_{3}$, (c) $\mathrm{Bi}_{0.93} \mathrm{La}_{0.07} \mathrm{FeO}_{3}$ and (d) $\mathrm{Bi}_{0.85} \mathrm{La}_{0.15} \mathrm{FeO}_{3}$.

Multiferroic character and homogeneity of SPS pellets was studied by DSC. Fig. 10 shows the DSC traces obtained on heating, where weak second-order antiferromagnetic-paramagnetic transitions and stronger first-order ferroelectric-paraelectric transitions are observed. DSC traces for $\mathrm{BiFeO}_{3}$ sintered by SPS have been already reported. ${ }^{26,28}$ As La content increases, Néel temperature increases and Curie temperature decreases.

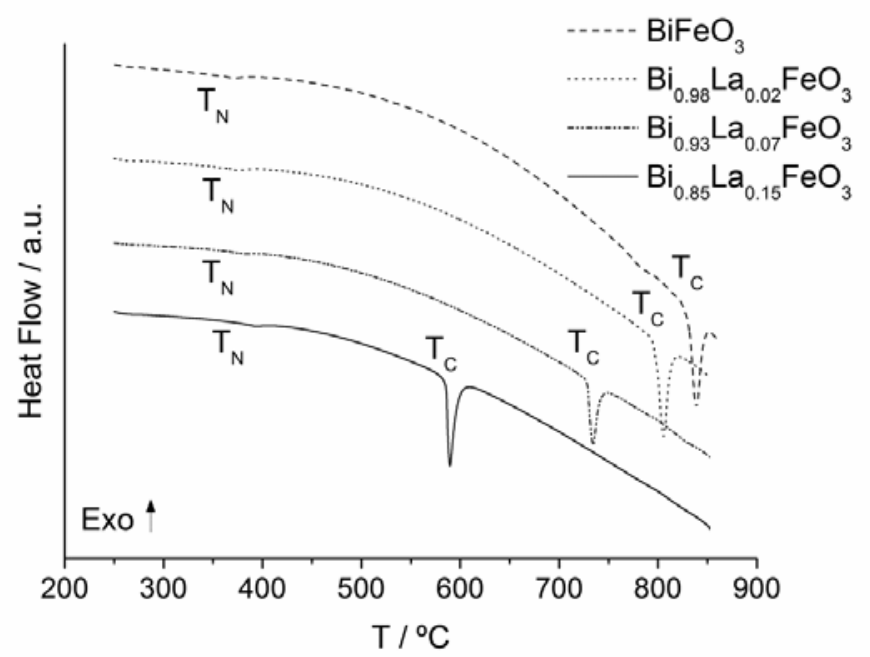

Fig. 10. DSC traces recorded for pellets sintered by SPS at $625^{\circ} \mathrm{C}$ and $75 \mathrm{MPa}$ for $\mathrm{BiFeO}_{3}$ and $\mathrm{Bi}_{0.98} \mathrm{La}_{0.02} \mathrm{FeO}_{3}$; and at $650^{\circ} \mathrm{C}$ and $75 \mathrm{MPa}$ for $\mathrm{Bi}_{0.93} \mathrm{La}_{0.07} \mathrm{FeO}_{3}$ and $\mathrm{Bi}_{0.85} \mathrm{La}_{0.15} \mathrm{FeO}_{3}$. Néel and Curie temperatures are labelled as $\mathrm{T}_{\mathrm{N}}$ and $\mathrm{T}_{\mathrm{C}}$ respectively. 
Table 4 presents transition temperatures for the samples studied; both $T_{N}$ and $T_{C}$ are coincident with those presented for samples prepared by different methods, demonstrating again the high quality and homogeneity of the pellets. ${ }^{28,30,34-36}$

Table 4. Néel and Curie temperatures, as obtained by DSC, for the samples sintered by SPS as a function of the lanthanum content.

\begin{tabular}{ccc}
$\begin{array}{c}\text { Composition } \\
(\mathrm{x})\end{array}$ & $\mathrm{T}_{\mathrm{N}}\left({ }^{\circ} \mathrm{C}\right)$ & $\mathrm{T}_{\mathrm{C}}\left({ }^{\circ} \mathrm{C}\right)$ \\
0 & 359.5 & 831.3 \\
0.02 & 364.4 & 797.8 \\
0.07 & 372 & 727.7 \\
0.15 & 382.4 & 585.9 \\
\hline
\end{tabular}

Thus, pellets sintered by SPS were obtained as pure phases over a very narrow range of temperatures, where both applied pressure and temperature play a very important role in the final density, in such a way that the densities obtained are higher than those reported by other authors. ${ }^{23,25}$

Impedance data of the SPS pellet for $\mathrm{x}=0.02$ are shown in Fig. 11. The impedance complex plane plot presents a high frequency, semicircular arc followed by an additional small low frequency arc (Fig. 11a). This arc appears in the C' data (Fig. 11b) as a dispersion to a higher capacitance value of $\sim 2 \mathrm{nFcm}^{-1}$ at low frequencies and can be attributed to grain boundaries or surface layers in the ceramic which are reduced to a different extent than the bulk. Similar behavior was observed for the other La-substituted compositions.

A post-sinter oxidative anneal was performed by heating the pellets at $600^{\circ} \mathrm{C}$ in air, to fully reoxidise both grain and grain boundary regions. Results for $\mathrm{x}=0.02$ are presented in Fig. 12. The impedance complex plane plot (Fig. 12a) shows a single, almost ideal arc whose low frequency intercept gives a total resistance of the sample about six times higher than that of the non-annealed sample (Fig. 11a). M" and Z", spectra show a single peak at almost coincident frequencies (Fig. 12b), which indicates the electrical homogeneity of the sample. Capacitance data (Fig. 12c) show a high frequency plateau at about $15 \mathrm{pFcm}^{-1}$ which corresponds to a permittivity of $\sim 150$ and represents the bulk response of the sample. At lower frequencies, a small increase in $\mathrm{C}^{\prime}$ is observed, indicating a possible power law response. Conductivity data (Fig. 12d) show a low frequency plateau that corresponds to the sample bulk conductivity and a dispersion at higher frequencies, again indicating a possible power law response. ${ }^{37,38}$ These data may be represented, to a first approximation, by a parallel R-C-CPE element, in which CPE is a Constant Phase Element responsible for the dispersion seen in $C^{\prime}$ at low frequencies and $\mathrm{Y}^{\prime}$ at high frequencies. 

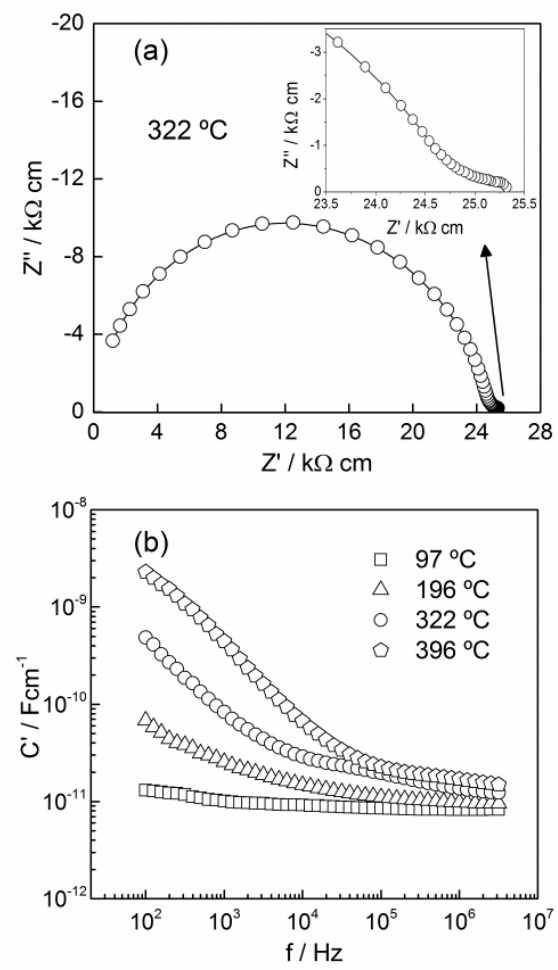

Fig. 11. (a) Impedance plot and (b) C' vs frequency for a non-annealed pellet of $x=0.02$. Data were recorded in an atmosphere of $\mathrm{N}_{2}$ to avoid sample oxidation during impedance measurements.
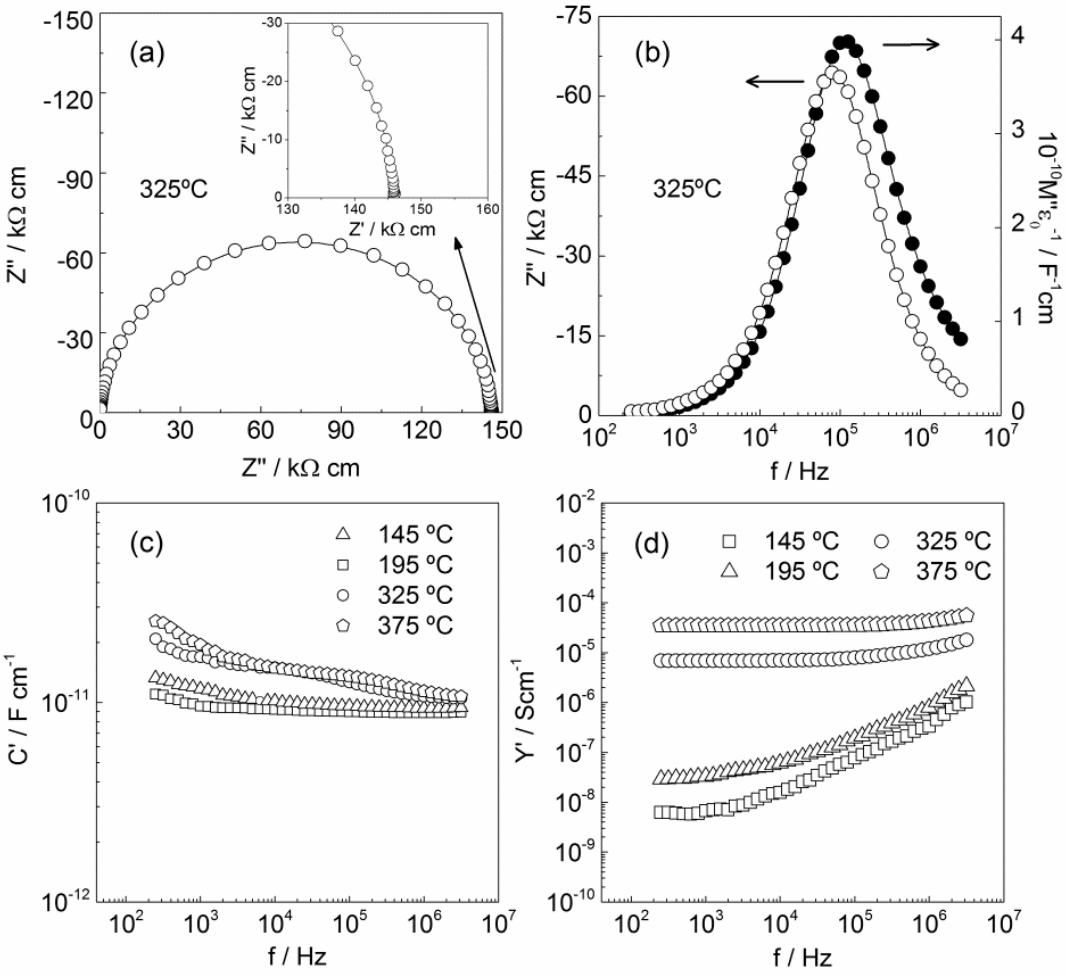

Fig. 12. (a) Impedance plots, (b) Z'/M" spectroscopic plots and (c) C'and (d) $\mathrm{Y}$ ' vs frequency for $\mathrm{Bi}_{0.98} \mathrm{La}_{0.02} \mathrm{FeO}_{3}$ sintered by SPS at $625^{\circ} \mathrm{C}$ and annealed at $600^{\circ} \mathrm{C}$ in air for 2 hours. 
Fig. 13 presents bulk conductivity data in Arrhenius format for $x=0.15$. The SPS sample without the post-sinter anneal had higher conductivity and lower activation energy, i.e. $0.81 \mathrm{eV}$, than the annealed sample, $1.12 \mathrm{eV}$, indicating reduction of the sample by the SPS process.

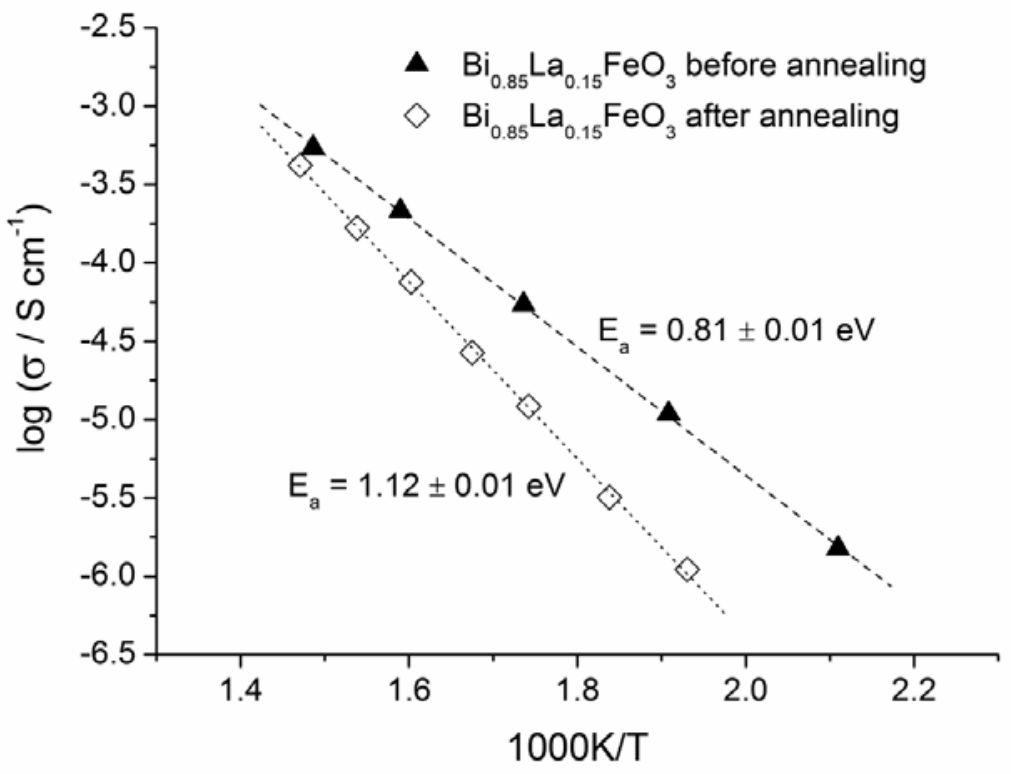

Fig. 13. Bulk conductivity data for $\mathrm{Bi}_{0.85} \mathrm{La}_{0.15} \mathrm{FeO}_{3}$ ceramics sintered by SPS before and after post-sinter annealing in air at $600^{\circ} \mathrm{C}$.

After post-sinter annealing, all samples are highly insulating at room temperature and showed modest levels of semiconductivity above $\sim 250^{\circ} \mathrm{C}$; resistance values are shown in conventional Arrhenius format in Fig. 14 for the three samples studied, together with $\mathrm{BiFeO}_{3}$ for comparison. ${ }^{28}$ The bulk resistivity at room temperature extrapolated from the high temperature data is $\sim 10^{15}$ $-2 \times 10^{14} \Omega \mathrm{cm}$. Conductivity increases with $\mathrm{x}$ and the activation energies are comparable indicating an increase in number of charge carriers with $\mathrm{x}$, as observed previously for samples of the system $\mathrm{Bi}_{1-\mathrm{x}} \mathrm{La}_{\mathrm{x}} \mathrm{FeO}_{3}(0 \leq \mathrm{x} \leq 0.15)$ sintered conventionally. ${ }^{30}$ The low conductivity of these samples implies that the SPS process followed by reoxidation does not produce mixed valence of $\mathrm{Fe}$ or oxygen non-stoichiometry. Thus, the objective of producing low conductivity materials has been achieved. 


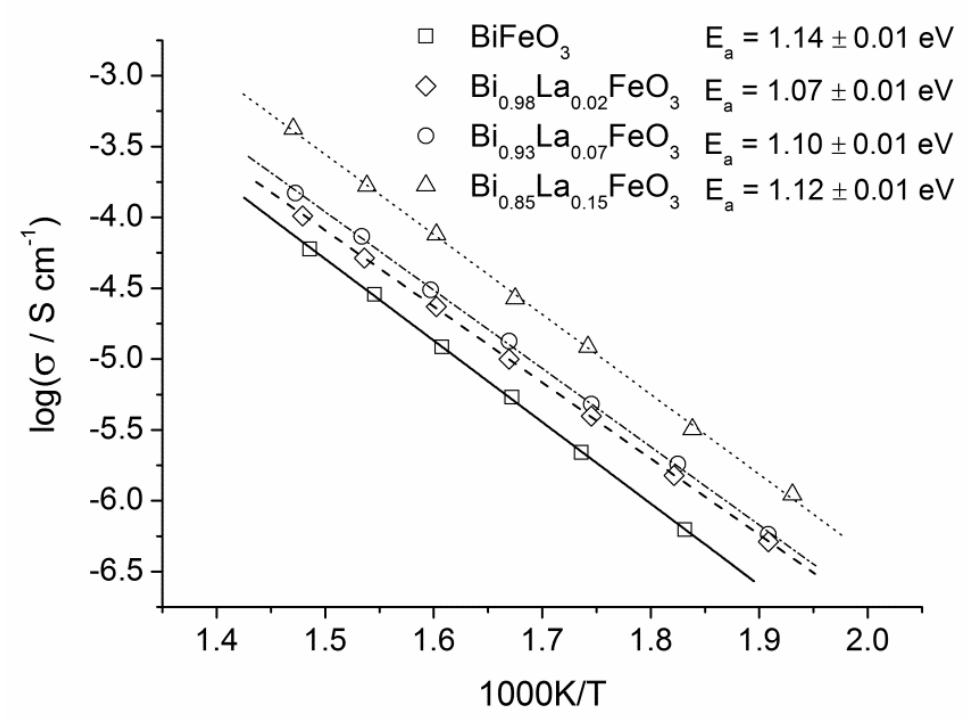

Fig. 14. Bulk conductivity data for $\mathrm{Bi}_{1-\mathrm{x}} \mathrm{La}_{\mathrm{x}} \mathrm{FeO}_{3}$ ceramics sintered by SPS and annealed at $600^{\circ} \mathrm{C}$ in air for 2 hours.

The conduction mechanism of these samples was studied by recording impedance data in three different atmospheres, i.e. air, oxygen and nitrogen as shown in Fig. 15 at $400^{\circ} \mathrm{C}$ for $\mathrm{Bi}_{0.93} \mathrm{La}_{0.07} \mathrm{FeO}_{3}$. These results show that the conduction is p-type since the resistivity of the samples decreased as the $\mathrm{pO}_{2}$ increased. This means that the samples can pick up oxygen by the mechanism:

$O_{2} \rightarrow 2 O^{2-}+4 h^{\bullet}$

The origin of the holes is not known. Conductivity measurements as function of $\mathrm{pO}_{2}$ at several temperatures are underway to determine the charge compensation mechanism.

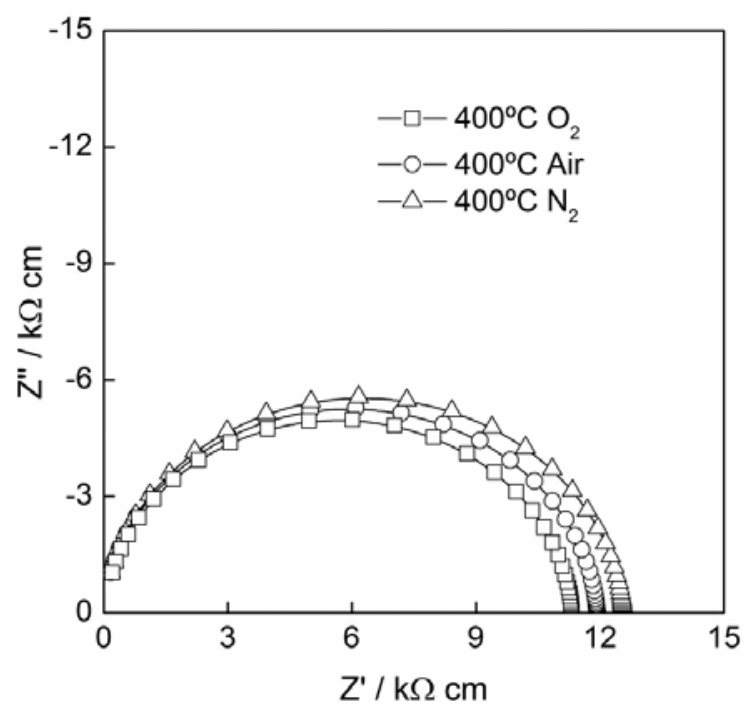

Fig. 15. Impedance complex-plane plots at $400^{\circ} \mathrm{C}$ in air, oxygen and nitrogen for $\mathrm{Bi}_{0.93} \mathrm{La}_{0.07} \mathrm{FeO}_{3}$ sintered by SPS and annealed at $600^{\circ} \mathrm{C}$. 


\section{Conclusions}

It is possible to prepare high density, phase-pure pellets of $\mathrm{Bi}_{1-\mathrm{x}} \mathrm{La}_{\mathrm{x}} \mathrm{FeO}_{3}, 0 \leq \mathrm{x} \leq 0.15$, using nanosized powders obtained by mechanosynthesis, by either conventional sintering at $850^{\circ} \mathrm{C}$ or spark plasma sintering, avoiding the formation of secondary phases. Pellets have been characterized and their high quality demonstrated by XRD, EDX, Raman and DSC. For conventionally-sintered pellets, there is a clear influence of the La content on the density of the pellets; the experimental conditions were carefully optimized to obtain high density nanostructured pellets by SPS at low temperature $\left(625^{\circ} \mathrm{C}-650^{\circ} \mathrm{C}\right)$. Pellets prepared conventionally present grain sizes from $5 \mu \mathrm{m}$ to less than $1 \mu \mathrm{m}$ depending on the La content and the density of the green pellets, whereas grain sizes of pellets obtained by SPS are in the range from 50-100 $\mathrm{nm}$. DSC depicts the antiferromagnetic-paramagnetic and ferroelectric-paraelectric transitions. Impedance spectroscopy measurements show that the samples sintered by SPS and annealed at $600^{\circ} \mathrm{C}$ are electrically homogeneous, with low conductivity that increases with $\mathrm{x}$, and p-type conduction mechanism.

\section{Acknowledgments}

Financial support from project CTQ2011-27626 (Spanish Ministerio de Economía y Competitividad), Junta de Andalucía (TEP-7858 and TEP-1900) and FEDER funds are acknowledged.

\section{Supplementary data}

Dilatometric curves for La-substituted $\mathrm{BiFeO}_{3}(\mathrm{x}=0.02,0.07,015)$ green pellets together with the X-ray diffraction pattern of the sintered samples. Tables and XRD patters of the results obtained by SPS.

\section{References}

1. Safi, R.; Shokrollahi, H. Physics, chemistry and synthesis methods of nanostructured bismuth ferrite $\mathrm{BiFeO}_{3}$ as a ferroelectro-magnetic material. Prog. Solid State Chem. 2012, 40, 6-15. 
2. Rojac, T.; Bencan, A.; Malic, B.; Tutuncu, G.; Jones, J. L.; Daniels, J. E.; Damjanovic, D. $\mathrm{BiFeO}_{3}$ Ceramics: Processing, Electrical, and Electromechanical Properties. J. Am. Ceram. Soc. 2014, 97, 1993-2011.

3. Perejón, A.; Sánchez-Jiménez, P. E.; Criado, J. M.; Pérez-Maqueda, L. A. Thermal Stability of Multiferroic $\mathrm{BiFeO}_{3}$ : Kinetic Nature of the $\beta-\gamma$ Transition and Peritectic Decomposition. J. Phys. Chem. C 2014, 118, 26387-26395.

4. Selbach, S. M.; Einarsrud, M.-A.; Grande, T. On the Thermodynamic Stability of BiFeO Chem. Mater. 2008, 21, 169-173.

5. Valant, M.; Axelsson, A.-K.; Alford, N. Peculiarities of a solid-state synthesis of multiferroic polycrystalline $\mathrm{BiFeO}_{3}$. Chem. Mater. 2007, 19, 5431-5436.

6. Bucci, J. D.; Robertso.Bk; James, W. J. Precision determination of lattice parameters and coefficients of thermal expansion of $\mathrm{BiFeO}_{3}$. J. Appl. Crystallogr. 1972, 5, 187-191.

7. Bernardo, M. S.; Jardiel, T.; Peiteado, M.; Caballero, A. C.; Villegas, M. Reaction pathways in the solid state synthesis of multiferroic $\mathrm{BiFeO}_{3}$. J. Eur. Ceram. Soc. 2011, 31, 3047-3053.

8. Chen, J. C., Wu, J. M. Dielectric properties and ac conductivities of dense single-phased $\mathrm{BiFeO}_{3}$ ceramics. Appl. Phys. Lett. 2007, 91, 182903.

9. Hunpratub, S.; Thongbai, P.; Yamwong, T.; Yimnirun, R.; Maensiri, S. Dielectric relaxations and dielectric response in multiferroic $\mathrm{BiFeO}_{3}$ ceramics. Appl. Phys. Lett. 2009, 94, 062904.

10. Jia, D. C.; Xu, J. H.; Ke, H.; Wang, W.; Zhou, Y. Structure and multiferroic properties of $\mathrm{BiFeO}_{3}$ powders. J. Eur. Ceram. Soc. 2009, 29, 3099-3103.

11. Kim, J. K.; Kim, S. S.; Kim, W. J. Sol-gel synthesis and properties of multiferroic $\mathrm{BiFeO}_{3}$. Mater. Lett. 2005, 59, 4006-4009.

12. Pradhan, A. K.; Zhang, K.; Hunter, D.; Dadson, J. B.; Loiutts, G. B.; Bhattacharya, P.; Katiyar, R.; Zhang, J.; Sellmyer, D. J.; Roy, U. N., et al. Magnetic and electrical properties of single-phase multiferroic $\mathrm{BiFeO}_{3}$. J. Appl. Phys. 2005, 97, 093903.

13. Wang, Y. P.; Zhou, L.; Zhang, M. F.; Chen, X. Y.; Liu, J. M.; Liu, Z. G. Room-temperature saturated ferroelectric polarization in $\mathrm{BiFeO}_{3}$ ceramics synthesized by rapid liquid phase sintering. Appl. Phys. Lett. 2004, 84, 1731-1733.

14. Yuan, G. L.; Or, S. W.; Wang, Y. P.; Liu, Z. G.; Liu, J. M. Preparation and multi-properties of insulated single-phase $\mathrm{BiFeO}_{3}$ ceramics. Solid State Commun. 2006, 138, 76-81.

15. Das, N.; Majumdar, R.; Sen, A.; Maiti, H. S. Nanosized bismuth ferrite powder prepared through sonochemical and microemulsion techniques. Mater. Lett. 2007, 61, 21002104.

16. Cheng, Z. X.; Li, A. H.; Wang, X. L.; Dou, S. X.; Ozawa, K.; Kimura, H.; Zhang, S. J.; Shrout, T. R. Structure, ferroelectric properties, and magnetic properties of the La-doped bismuth ferrite. J. Appl. Phys. 2008, 103, $07 \mathrm{E} 507$.

17. Du, Y.; Cheng, Z. X.; Shahbazi, M.; Collings, E. W.; Dou, S. X.; Wang, X. L. Enhancement of ferromagnetic and dielectric properties in lanthanum doped $\mathrm{BiFeO}_{3}$ by hydrothermal synthesis. J. Alloys Compd. 2010, 490, 637-641.

18. Yuan, G. L.; Baba-Kishi, K. Z.; Liu, J. M.; Or, S. W.; Wang, Y. P.; Liu, Z. G. Multiferroic properties of single-phase $\mathrm{Bi}_{0.85} \mathrm{La}_{0.15} \mathrm{FeO}_{3}$ lead-free ceramics. J. Am. Ceram. Soc. 2006, 89, 3136-3139.

19. Wang, S. Y.; Qiu, X.; Gao, J.; Feng, Y.; Su, W. N.; Zheng, J. X.; Yu, D. S.; Li, D. J. Electrical reliability and leakage mechanisms in highly resistive multiferroic $\mathrm{La}_{0.1} \mathrm{Bi}_{0.9} \mathrm{FeO}_{3}$ ceramics. Appl. Phys. Lett. 2011, 98, 152902.

20. Jiang, Q. H.; Nan, C. W.; Shen, Z. J. Synthesis and properties of multiferroic La-modified $\mathrm{BiFeO}_{3}$ ceramics. J. Am. Ceram. Soc. 2006, 89, 2123-2127.

21. Munir, Z. A.; Anselmi-Tamburini, U.; Ohyanagi, M. The effect of electric field and pressure on the synthesis and consolidation of materials: A review of the spark plasma sintering method. J. Mater. Sci. 2006, 41, 763-777. 
22. Omori, M. Sintering, consolidation, reaction and crystal growth by the spark plasma system (SPS). Mater. Sci. Eng., A 2000, 287, 183-188.

23. Dai, Z. H.; Akishige, Y. Electrical properties of multiferroic $\mathrm{BiFeO}_{3}$ ceramics synthesized by spark plasma sintering. J. Phys. D: Appl. Phys. 2010, 43, 445403

24. Jiang, Q. H.; Nan, C. W.; Wang, Y.; Liu, Y. H.; Shen, Z. J. Synthesis and properties of multiferroic $\mathrm{BiFeO}_{3}$ ceramics. J. Electroceram. 2008, 21, 690-693.

25. Mazumder, R.; Chakravarty, D.; Bhattacharya, D.; Sen, A. Spark plasma sintering of $\mathrm{BiFeO}_{3}$. Mater. Res. Bull. 2009, 44, 555-559.

26. Wang, L. C.; Wang, Z. H.; He, S. L.; Li, X.; Lin, P. T.; Sun, J. R.; Shen, B. G. Enhanced magnetization and suppressed current leakage in $\mathrm{BiFeO}_{3}$ ceramics prepared by spark plasma sintering of sol-gel derived nanoparticles. Physica B 2012, 407, 1196-1202.

27. Correas, C.; Hungria, T.; Castro, A. Mechanosynthesis of the whole $\mathrm{xBiFeO}_{3}-(1-\mathrm{x}) \mathrm{PbTiO}_{3}$ multiferroic system: structural characterization and study of phase transitions. $J$. Mater. Chem. 2011, 21, 3125-3132.

28. Perejon, A.; Maso, N.; West, A. R.; Sanchez-Jimenez, P. E.; Poyato, R.; Criado, J. M.; Perez-Maqueda, L. A. Electrical Properties of Stoichiometric $\mathrm{BiFeO}_{3}$ Prepared by Mechanosynthesis with Either Conventional or Spark Plasma Sintering. J. Am. Ceram. Soc. 2013, 96, 1220-1227.

29. Jiang, Q. H.; Ma, J.; Lin, Y. H.; Nan, C. W.; Shi, Z.; Shen, Z. J. Multiferroic properties of $\mathrm{Bi}_{0.87} \mathrm{La}_{0.05} \mathrm{~Tb}_{0.08} \mathrm{FeO}_{3}$ ceramics prepared by spark plasma sintering. Appl. Phys. Lett. 2007, 91, 022914.

30. Perejon, A.; Sanchez-Jimenez, P. E.; Perez-Maqueda, L. A.; Criado, J. M.; Romero de Paz, J.; Saez-Puche, R.; Maso, N.; West, A. R. Single phase, electrically insulating, multiferroic La-substituted $\mathrm{BiFeO}_{3}$ prepared by mechanosynthesis. J. Mater. Chem. $\mathrm{C}$ 2014, 2, 8398-8411.

31. Sagdahl, L. T.; Einarsrud, M.-A.; Grande, T. Sintering of $\mathrm{LaFeO}_{3}$ Ceramics. J. Am. Ceram. Soc. 2000, 83, 2318-2320.

32. Garcia, F. G.; Riccardi, C. S.; Simoes, A. Z. Lanthanum doped $\mathrm{BiFeO}_{3}$ powders: Syntheses and characterization. J. Alloys Compd. 2010, 501, 25-29.

33. Yang, Y.; Liu, Y. L.; Zhu, K.; Zhang, L. Y.; Ma, S. Y.; Liu, J. E.; Jiang, Y. J. Structural properties of $\mathrm{Bi}_{1-x} \mathrm{La}_{x} \mathrm{FeO}_{3}$ studied by micro-Raman scattering. Chin. Phys. B 2010, 19, 037802.

34. Rusakov, D. A.; Abakumov, A. M.; Yamaura, K.; Belik, A. A.; Van Tendeloo, G.; Takayama-Muromachi, E. Structural Evolution of the $\mathrm{BiFeO}_{3}-\mathrm{LaFeO}_{3}$ System. Chem. Mater. 2011, 23, 285-292.

35. Yan, X.; Chen, J.; Qi, Y.; Cheng, J.; Meng, Z. Hydrothermal synthesis and characterization of multiferroic $\mathrm{Bi}_{1-x} \mathrm{La}_{x} \mathrm{FeO}_{3}$ crystallites. J. Eur. Ceram. Soc. 2010, 30, 265-269.

36. Chen, J. R.; Wang, W. L.; Lia, J. B.; Rao, G. H. X-ray diffraction analysis and specific heat capacity of $\mathrm{Bi}_{1-x} \mathrm{La}_{x} \mathrm{FeO}_{3}$ perovskites. J. Alloys Compd. 2008, 459, 66-70.

37. Jonsher, A. K., Dielectric Relaxation in Solids, Chelsea Dielectric Press, London, 1983.

38. Jonsher, A. K., Universal Relaxation Law, Chelsea Dielectric Press, London, 1996. 